\title{
PRESENÇA DE SEMENTES ESVERDEADAS EM SOJA E SEUS EFEITOS SOBRE SEU POTENCIAL FISIOLÓGICO ${ }^{1}$
}

\author{
MARIADE FÁTIMAZORATO², SILMARTEICHERT PESKEE ${ }^{3}$, CLAUDIOTAKEDA ${ }^{4}$ E JOSÉ DE BARROS FRANÇANETO ${ }^{5}$
}

\begin{abstract}
RESUMO - Sementes de soja, sobretudo em Mato Grosso, região dos cerrados, tem apresentado cotilédones com degradação parcial de clorofila. A conseqüência direta desse fenômeno é o descarte de muitos lotes, resultado de sua baixa qualidade. Com o objetivo de averiguar a influência exercida pela clorofila na qualidade fisiológica em sementes de soja foi desenvolvido este estudo. Foram utilizados dois lotes comerciais (A e B) da cultivar MG/BR46-Conquista, ciclo precoce com 11,8\% e $37,4 \%$, de sementes esverdeadas, segmentados em três amostras: sementes sem manipulação (lote original), sementes esverdeadas e sementes amarelas. Cada amostra consistiu de um tratamento. Através dos testes de germinação, envelhecimento acelerado (24 horas), tetrazólio, comprimento de plântula, massa de mil sementes, condutividade elétrica e emergência em campo foi realizada a avaliação da qualidade das sementes, no momento de semeadura. As sementes esverdeadas apresentaram menor germinação, viabilidade e vigor, maiores desuniformidade de plântulas, taxa de deterioração e quantidade de lixiviados, menores comprimento de plântulas e peso de mil sementes e baixa capacidade de emergência em campo, indiferente ao índice porcentual de cotilédones com pigmentação verde, porém, o prejuízo foi maior no lote $\mathrm{B}$, com 37,4\% de sementes esverdeadas. Pode-se inferir que clorofila é indicativo de redução do potencial fisiológico em sementes de soja.
\end{abstract}

Termos para indexação: Glycine max, cotilédones esverdeados, senescência, deterioração, clorofila.

\section{GREEN SOYBEAN SEED AND EFFECTS ON ITS PHYSIOLOGICALPOTENTIAL}

\begin{abstract}
Soybean seed, mainly from the state of Mato Grosso, savannah (cerrado) region, has presented cotyledons with partial degradation of chlorophyll. The consequence of this phenomenon has been the discard of many seed lots, as result of their low quality. This study was developed with the objective of investigating the influence played by chlorophyll, over the physiological quality of soybean seed. Two commercial seed lots (A and B) of the cultivar MG/ BR46-Conquista, early maturing cycle, with $11,8 \%$ and $37,4 \%$ of green seeds, respectively were segmented into three samples: original seed, green seed and yellow seed. Each sample composed one treatment. Seed quality evaluation was determined by the germination test, accelerated aging (24 hours), tetrazolium test, seedling and radicle length, weight of a thousand seeds, electric conductivity, field emergence, all test performed at the time of planting. Green seed presented lower germination, viability and vigor, and a lower level of uniformity between the seedlings, a faster rate of deterioration, higher quantity of leachate, shorter plant length, lower one thousand seed weight, and a lower germination capacity in the field, independent of the quantity of the percentage of cotyledons with green pigmentation. However these losses were higher in the lot with $37.4 \%$ green seed. It can be concluded that chlorophyll is an indication of reduction of the physiological potential in soybean seeds.
\end{abstract}

Index terms: Glycine max, green cotyledons, senescence, deterioration, chlorophyll.

${ }^{1}$ Submetido em 20/03/2006. Aceito para publicação em 09/01/2007. Parte da tese de Doutorado apresentada pelo primeiro autor ao Programa de Pós-Graduação em Ciência e Tecnologia de Sementes, FAEM, UFPel.

${ }^{2}$ Bióloga, bolsista do CNPq, Depto de Fitotecnia, FAEM, UFPel, Coordenadora Técnica, Aprosmat, Cx. Postal, 81, 78745-280, Rondonópolis, MT; fzorato@terra.com.br
${ }^{3}$ Eng $^{\circ}$ Agr $^{\circ}$, Ph.D., Prof. Titular, Depto de Fitotecnia, FAEM, UFPel; peske@ufpel.tche.br

${ }^{4}$ Eng $^{\circ} \mathrm{Agr}^{\circ}$, Dr., Coordenador de melhoramento, Fundação MT; takeda@fundacaomt.com.br

${ }^{5}$ Eng $^{\circ} \mathrm{Agr}^{\mathrm{o}}$, Ph.D., Pesquisador, Embrapa Soja; jbfranca@ cnpso.embrapa.br 


\section{INTRODUÇÃO}

A produção brasileira de soja (Glycine max (L.) Merrill), sobretudo no Centro-Oeste, região dos cerrados, tem sido afetada por um fenômeno também preocupante em outros países, a retenção de clorofila nas sementes. Os cotilédones apresentam vestígios do pigmento verde e a conseqüência verificada na produção de sementes é o decréscimo do vigor e da viabilidade.

Sementes esverdeadas, no Estado de Mato Grosso, tem propiciado prejuízos na emergência em campo, dificultando a formação de estandes recomendados para as diferentes cultivares, assim como, muito descarte de lotes de sementes, no momento de semeadura, resultado de sua baixa qualidade fisiológica.

A indústria, outro segmento da cadeia da soja, do mesmo modo, tem apresentado problemas decorrentes de recebimento de grãos ou sementes esverdeadas, em razão da clorofila ser uma molécula prooxidante, reduzir a estabilidade oxidativa do óleo, além de diminuir a velocidade do processo de hidrogenação devido a clorofila bloquear os centros ativos do catalisador (Endo et al., 1984; Usuki et al., 1984; Ward et al., 1992 e 1995; Jalink et al., 1999; Sinnecker, 2002).

O teor de clorofila em sementes de soja é determinado pelo genótipo e sofre uma variação significativa entre as cultivares. Esse nível pode ser afetado, tanto pelo estádio de maturação como pelas condições de secagem, ou pelas condições climáticas que podem interferir no amadurecimento normal em campo (Sinnecker, 2002).

Abordagens são registradas causadoras de sementes verdes em lavouras de soja, a exemplo da desuniformidade de maturação, ataques de insetos, principalmente, percevejos que causam a retenção de hastes verdes (Câmara e Heiffig, 2000). Outros fatores que predispõem a soja à expressão de sementes esverdeadas, de acordo com França-Neto et al. (2005), são os estresses bióticos e abióticos, que resultam na morte prematura da planta ou em maturação forçada. Dentre os estresses bióticos citam as doenças de raiz, como fusariose, de colmo, como cancro da haste, e de folhas, como a ferrugem asiática e como abióticos, o manejo inadequado, como distribuição irregular de calcário ou de fertilizantes, dessecante aplicando antes do estádio ideal, déficit hídrico associado com temperaturas elevadas.

$\mathrm{Na}$ discussão específica deste ensaio, os aspectos encontrados nos campos de produção de sementes, nas plantas a partir do estádio $R_{7}$ (maturidade fisiológica) até $R_{8}$ (colheita), não se evidenciam distúrbios na fenologia, ou seja, a planta sofre a senescência, seguindo um padrão de coloração normal de maturação, em relação ao total da população. Entretanto, na debulha de vagens, pode se observar algumas sementes com os cotilédones visivelmente esverdeados, sendo a localização destas sementes aleatória, tanto na planta quanto na vagem.

A hipótese que, de forma provável justifica a alteração de físiologia das sementes na região dos cerrados, é a ocorrência de estresse hídrico, associado às condições do microclima, a exemplo da alta temperatura do ar (acima de $30^{\circ} \mathrm{C}$ ), baixa umidade relativa (abaixo de $50 \%$ ), elevada intensidade luminosa, baixa retenção de umidade nos diferentes solos, principalmente os arenosos e, alta taxa de evaporação, no período considerado fundamental, para a degradação da clorofila, o qual de acordo com Fukushima e Lanfer-Marquez (2000), transcorre na passagem do estádio $\mathrm{R}_{6}$ para o estádio $\mathrm{R}_{7}$.

Adams et al. (1983), estudando soja e Ward et al. (1992, 1995), canola, observaram em campo, que quando a colheita foi realizada em condições de alta temperatura e baixa umidade relativa, com rápida perda de umidade, ou quando foram aplicados produtos químicos dessecantes na cultura para acelerar o amadurecimento, houve a ocorrência de sementes verdes. De acordo com Sinnecker (2002), as clorofilas são ésteres, extremamente lábeis, sensíveis à luz, ao oxigênio e à degradação química.

Nos estádios finais de maturação ocorre uma brusca perda de umidade devido à interrupção de translocação de água e matéria orgânica para as sementes, quando a planta, a partir desse ponto, inicia a senescência e perde água por evaporação (Sinnecker, 2002). A drástica redução no conteúdo de água, com a aproximação da maturidade, explica a inibição de desenvolvimento e o declínio associado à atividade metabólica (McIntyre, 1987). De acordo com Guiamét et al. (1991), o desenvolvimento de sementes está correlacionado com o amarelecimento das vagens e das folhas, fazendo parte da síndrome da senescência monocárpica, que Noodén (1984) definiu como sendo a degeneração que conduz à morte do organismo inteiro, no final da fase reprodutiva.

De forma simultânea, com a maturação das sementes, ocorre a degradação da clorofila presente, a síntese de açúcares solúveis e modificações nas proteínas solúveis (Adams et al., 1983; Steckel et al., 1989; Ward et al., 1992, 1995). No momento da aquisição de tolerância à dessecação, a clorofila é fotossinteticamente inativa, devido ao metabolismo das sementes ser interrompido (Jalink et al., 1998). Todavia, pouco é o conhecimento sobre a fisiologia e a bioquímica de degradação da clorofila (Ward et al., 1992, 1995). 
As sementes desidratadas de maneira rápida não têm as clorofilas degradadas na mesma taxa como as sementes desidratadas de forma lenta, que apresentam $1 \mu \mathrm{g}$ clorofila.semente ${ }^{-1}$. As sementes permanecem visivelmente verdes quando desidratadas rapidamente, chegando apresentar até $29 \mu \mathrm{g}$ clorofila.semente ${ }^{-1}$ (Adams et al., 1983). Corroborando com essas informações, Sinnecker, (2002) observou em campo, no avanço da maturação em soja ou em sementes colhidas antes do período de maturidade fisiológica, submetidas à secagem lenta à temperatura ambiente $\left(25^{\circ} \mathrm{C}\right)$, um sistema enzimático envolvendo as enzimas oxigenases, que atuaram degradando o pigmento verde para compostos incolores. Entretanto, observou, também, sementes que ainda não tinham completado seu ciclo quando expostas à secagem rápida em estufa, na temperatura de $40^{\circ} \mathrm{C}$, o mecanismo de degradação da clorofila parecendo ter ocorrido por duas vias: via enzimática, mediada por clorofilases, formando pigmentos defitilados (clorofilídeos e feoforbídeos); e via química, evidenciada pelo acúmulo de feofitinas (pigmento acessório do tipo clorofila que não possui íon magnésio).

A secagem reduz o teor de água, evitando a deterioração por reações enzimáticas ou por desenvolvimento de microrganismos, que produzem lipases hidrolíticas, tendo, como conseqüência, o teor de ácidos graxos livres aumentados (Pritchard, 1983; Sinnecker, 2002).

Ensaios de Jalink et al. (1999) denotaram a maturidade das sementes sendo importante para reduzir a possibilidade da clorofila produzir elétrons livres os quais podem causar injúria oxidativa. No relato dos autores, a deterioração das sementes durante o armazenamento tem, de forma freqüente, se relacionado a radicais livres, mediando prejuízos oxidativos às proteínas, aos ácidos nucléicos e às membranas.

Existe diversidade de situações em que a clorofila, pigmento verde que funciona como receptor da energia luminosa no processo de fotossíntese, se transforma em parâmetro negativo, propiciando redução de vigor e do poder germinativo em sementes de soja.

Com escassa informação na literatura e denotando importância cada vez maior de conhecimento dos mecanismos de ação das sementes esverdeadas, foi desenvolvido este estudo para averiguar a influência que a clorofila exerce no potencial fisiológico de sementes de soja.

\section{MATERIAL E MÉTODOS}

Foram utilizados dois lotes comerciais de sementes de soja, cultivar MG/BR46-Conquista, ciclo precoce, produzidos na safra agrícola 1999/2000, na região sul do Mato Grosso. Os lotes foram previamente selecionados de acordo com a presença visual de sementes esverdeadas, os quais apresentaram $11,8 \%$ e $37,4 \%$ e foram denominados de Lote A e Lote B, respectivamente. Para cada lote foram trabalhadas três amostras, segmentadas conforme a seguinte ordem: sementes representativas do lote original, sem manipulação e, sementes que foram escolhidas e retiradas do lote original e classificadas como: sem sinais visuais de pigmentação verde, consideradas sementes amarelas e sementes com nuances (diferentes tons) de pigmentos verdes, consideradas sementes esverdeadas. Cada amostra consistiu em um tratamento, sendo essa composta de aproximadamente $1,2 \mathrm{~kg}$ de sementes.

O critério utilizado para a obtenção da média porcentual de sementes esverdeadas nos lotes originais foi o seguinte: sob lupa circular de seis aumentos foram separadas 10 subamostras de 100 sementes cada, em quatro repetições, e contabilizada a presença ou a ausência de pigmento verde nos cotilédones das sementes, que não foram expostas a nenhum tratamento, a exemplo de pré-umedecimento. Foi considerada toda e qualquer nuance de pigmento nos cotilédones da semente, então retirada para contagem. Em caso de dúvida, foi retirado o tegumento da semente para melhor visualização e confirmação de vestígio (sinal) verde. Os resultados, expressos em números inteiros, foram computados para as 10 subamostras e realizada a média porcentual para cada repetição.

$\mathrm{Na}$ época de semeadura (novembro), no laboratório da Associação de Produtores de Sementes de Mato Grosso Aprosmat, Rondonópolis-MT, no laboratório de Tecnologia de Sementes da Embrapa Soja, Londrina-PR e no campo da Fazenda Girassol, Pedra Preta-MT, as sementes que permaneceram armazenadas em câmara controlada à temperatura de $20^{\circ} \mathrm{C} \pm 2^{\circ} \mathrm{C}$ e umidade relativa $50 \%$, no período de maio a novembro/2000, foram submetidas aos seguintes testes:

Teste de germinação - foram utilizadas quatro subamostras de 50 sementes em cada tratamento, por repetição. A semeadura foi realizada em rolo de papel-toalha, marca Germitest, umedecido com quantidade de água equivalente a 2,5 vezes o peso do substrato seco e colocado em germinador sob temperatura constante de $25^{\circ} \mathrm{C} \pm 1^{\circ} \mathrm{C}$. As avaliações foram efetuadas no quinto dia após instalação e o resultado expresso em porcentagem de plântulas normais, conforme critérios estabelecidos pelas Regras para Análise de Sementes (Brasil, 1992).

Envelhecimento acelerado - foram utilizadas 200 
sementes, para cada tratamento, por repetição. Foi adotada a metodologia recomendada pela AOSA(1983) e complementada por Marcos Filho (1999), com modificação no tempo de permanência das sementes na câmara e no substrato utilizado. As sementes foram distribuídas em camada uniforme sobre uma tela de alumínio fixada no interior de caixa plástica tipo gerbox, funcionando como um compartimento individual (mini-câmara). Em cada mini-câmara foram adicionados $40 \mathrm{~mL}$ de água e colocadas a seguir, em câmara tipo BOD (Eletrolab), regulada a $41^{\circ} \mathrm{C} \pm 1{ }^{\circ} \mathrm{C}$, por 24 horas. Após o período de exposição, duas subamostras de 100 sementes, para cada tratamento, por repetição, foram semeadas em areia.

Teste de tetrazólio - foi realizado empregando duas subamostras de 50 sementes, em cada tratamento, por repetição. As sementes foram pré-umedecidas em papel-toalha com água por 16 horas, à temperatura média de $25^{\circ} \mathrm{C}$. Após o período, as sementes foram colocadas em copos plásticos, submersas em solução $0,05 \%$ de sal de 2,3,5 trifenil cloreto de tetrazólio, por 150 minutos, à temperatura de $35^{\circ} \mathrm{C} \pm 1^{\circ} \mathrm{C}$, em estufa, no escuro. Vencido o período de coloração, a solução foi drenada e as sementes foram lavadas em água corrente. As avaliações de vigor e viabilidade, assim como os principais danos fisiológicos das sementes, foram de acordo com critérios de França Neto et al. (1998) e Zorato (2001).

Comprimento de plântula - foi efetuado com quatro subamostras de 10 sementes em cada tratamento, por repetição. A disposição das sementes foi no terço superior da folha de papel-toalha, marca Germitest, com o hilo voltado para a parte inferior, posição que facilita o desenvolvimento retilíneo da raíz e do hipocótilo e favorece a mensuração do comprimento. O substrato foi umedecido 2,5 vezes seu peso seco em água e os rolos foram colocados inclinados $\left(45^{\circ}\right) \mathrm{em}$ germinador, em ausência de luz, a $25^{\circ} \mathrm{C} \pm 1^{\circ} \mathrm{C}$, durante cinco dias. No final desse período, foram consideradas apenas as plântulas normais e obtidas as medidas em mm da extremidade da raiz até o ponto de inserção dos cotilédones (Nakagawa, 1999).

Massa de mil sementes - foram empregadas oito subamostras de 100 sementes, em cada tratamento, por repetição, de acordo com critérios das Regras para Análise de Sementes (Brasil, 1992).

Condutividade elétrica - teste realizado no laboratório de tecnologia de sementes, na Embrapa Soja, Londrina-PR, com uma subamostra de 100 sementes, para cada tratamento, por repetição. De acordo com os critérios de Vieira e Krzyzanowski (1999) as sementes foram acondicionadas para embeber em recipientes plásticos contendo uma célula para cada semente submersa em água destilada, por período de 24 horas à temperatura de $20^{\circ} \mathrm{C}$. Após esse período, seguiu-se a leitura em condutivímetro modelo ASA 610 (Agro-Science, Inc.) sendo o resultado expresso em porcentagem de viabilidade, tendo como referência o ponto de partição 90 $\mu$ A.semente ${ }^{-1}$.

Emergência em campo - teste foi realizado na Fazenda Girassol, município de Pedra Preta-MT, solo do tipo Latossolo Vermelho escuro distrófico, textura argilosa. 400 sementes (quatro subamostras de 100 sementes), em cada tratamento, por repetição foram semeadas em linhas de $1,50 \mathrm{~m}$ de comprimento, espaçadas de $0,50 \mathrm{~m}$, em sulcos de $0,03 \mathrm{~m}$ de profundidade. No período após semeadura e início de emergência foram utilizadas irrigações. Os resultados foram expressos em porcentagem de plântulas emergidas, avaliadas ao décimo segundo dia após a semeadura.

Procedimentos estatísticos - o delineamento experimental utilizado foi o de blocos casualizados, com quatro repetições e as médias comparadas pelo teste de Tukey, a $5 \%$. Os dados em porcentagens foram transformados em arc seno da raiz quadrada de $\mathrm{x} / 100$. As análises estatísticas foram executadas através do Sistema de Análise Estatística SANEST (Zonta e Machado, 1986).

\section{RESULTADOS E DISCUSSÃO}

Pelos resultados obtidos, foi constatada a presença de pigmentos verdes interferindo no vigor e no poder germinativo das sementes. Porém, ficou bem estabelecido na cultivar estudada, que sua influência é maior, quanto mais elevado for o porcentual de sementes esverdeadas presentes no lote e, no caso específico, o lote B que apresentava 37,4\%, em relação ao lote A com 11,8\%. Também foi possível evidenciar a tendência de redução da qualidade, nos testes efetuados, nos tratamentos que apresentavam todas as sementes com nuances da cor verde nos cotilédones (sementes com aparência em diferentes tons de verde), quando comparados com sementes originais (lotes sem manipulação) e com as sementes amarelas (retiradas as sementes esverdeadas).

No teste de germinação (Tabela 1), que nos relatos de Marcos Filho (1999) fornece informações sobre o potencial de uma amostra sob condições ótimas de ambiente, o porcentual de plântulas normais nos tratamentos com sementes esverdeadas foi inferior, quando relacionado aos tratamentos com sementes originais e sementes amarelas. Houve, também, nos lotes A e B, diferença significativa entre os tratamentos de sementes amarelas e de sementes originais, em razão dessas 
TABELA 1. Médias obtidas nos testes de germinação, envelhecimento acelerado 24 horas, emergência em campo, condutividade e massa de mil sementes, em dois lotes de sementes de soja A e B com 11,8\% e 37,4\%, respectivamente de sementes esverdeadas, segmentados em: semente original, semente amarela e semente esverdeada.

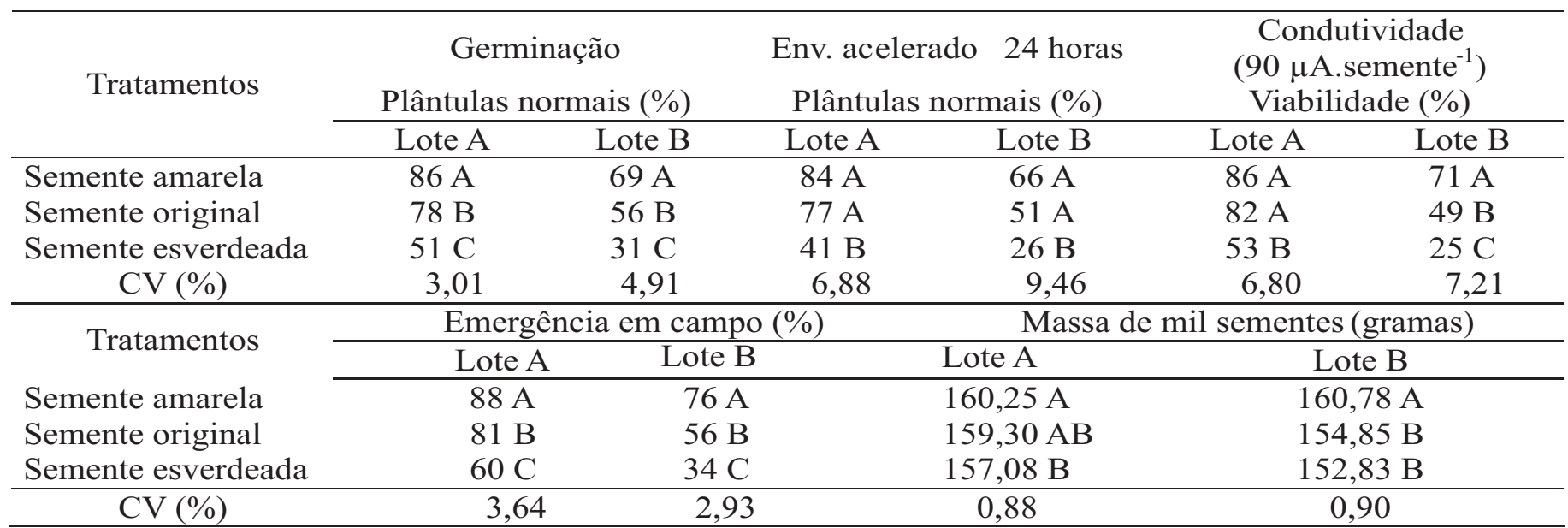

Médias seguidas pela mesma letra na coluna, não diferem entre si peloTeste de Tukey ao nível de 5\% de probabilidade de erro. Lote A (original): $11,8 \%$ de sementes esverdeadas e Lote B (original): $37,4 \%$ de sementes esverdeadas.

últimas apresentarem influência do pigmento verde.

As sementes com cotilédones esverdeados demonstraram baixa capacidade germinativa e desuniformidade quanto ao desempenho de plântulas, referente ao tamanho de plântula e formação do sistema radicular. No entanto, as sementes amarelas originaram plântulas que se caracterizaram, visualmente, por sistemas radiculares mais desenvolvidos, crescimento homogêneo e maior porcentagem de plântulas normais. Esses resultados reiteram os obtidos por Jalink et al. (1998), quando compararam baixo, médio e alto sinal de fluorescência de clorofila, verificando na amostra de alto sinal, desempenho significativamente reduzido em quase todos os aspectos, como exemplo, germinação, plântulas normais, taxa e uniformidade de germinação. Medina et al. (1997), também encontraram os índices de germinação superiores nos tratamentos em que foram retiradas as sementes esverdeadas e verdes. Jalink et al. (1999), observaram em sementes que fisiologicamente não completaram a maturação, baixo número de plântulas normais.

No teste de envelhecimento acelerado (Tabela 1), as sementes amarelas expressaram maior porcentual de plântulas normais, uniformidade nos tamanhos das plântulas e melhor desenvolvimento do sistema radicular, embora, não se diferenciando estatísticamente quando comparadas às sementes originais, nos dois lotes. Já, o efeito do envelhecimento sobre sementes com pigmento verde foi mais acentuado, mostrando taxa de deterioração avançada, nos dois lotes estudados, e diferiram de forma significativa das sementes originais e das sementes amarelas. Todavia, esta deterioração foi mais elevada no lote B com $37,4 \%$ de sementes esverdeadas, apresentando comprometimento quase total das células cotiledonares. Nos relatos de Mendonça et al. (2000), sementes de menor qualidade se deterioram de forma mais rápida do que as mais vigorosas, quando expostas às condições adversas de alta temperatura e umidade relativa no teste de envelhecimento acelerado.

De acordo com Endo et al. (1984), os produtos de oxidação da clorofila podem ter efeitos prooxidantes ou atividades fotooxidativas e a clorofila pode reagir com compostos intermediários de peroxidação de lipídios e peróxidos. Wilson e McDonald (1986) foram consistentes no relato de que a peroxidação de lipídios é uma das causas de deterioração das sementes e está correlacionada com o declínio de vigor e viabilidade.

Ainda em seus estudos, Endo et al. (1984) observaram que a clorofila foi oxidada pela enzima lipoxigenase na presença de ácidos graxos insaturados. Oxidações de ácidos graxos insaturados são apontados como reação primária no processo de envelhecimento, por produzirem radicais livres que atacam posteriormente lipídios, proteínas e ácidos nucléicos numa reação em cadeia (Harrington, 1973; Vertucci e Leopold, 1987). Reações de oxidações, no processo de envelhecimento, envolvem enzimas, tal como lipoxidase, e enzimas oxidativas podem funcionar em baixa atividade da água (Vertucci e Leopold, 1987), fatos esses que tornam mais compreensível o declínio do potencial fisiológico das sementes esverdeadas com o período de armazenagem.

No teste de tetrazólio (Tabela 2), o decréscimo da 
qualidade foi notório em sementes de cotilédones esverdeados, que mostraram sintomas caracterizados, no teste, como deterioração por umidade (DU). Essa notoriedade comprova os resultados obtidos por Costa et al. (2001) e França-Neto et al. (2005), os quais relacionaram índices de deterioração por umidade à incidência de sementes verdes e/ou esverdeadas.

$\mathrm{O}$ indicativo de altos porcentuais de deterioração por umidade foi categorizado na subclasse DU 4-5 - fator principal diferenciando os índices de vigor e viabilidade (Zorato, 2001) e fornecendo subsídios quanto ao potencial de armazenagem ou mesmo redução do potencial fisiológico no momento da semeadura. Com a manifestação de um dano de processo evolutivo, é possível justificar a redução da qualidade, principalmente de vigor, com o passar do tempo.

Ficou nítido que a abrangência da deterioração por umidade é preocupante nas diferentes regiões das sementes esverdeadas, desde que observadas as variabilidades nas tonalidades de verde. Existe a concordância da importância vital do eixo embrionário (plúmula e radícula) nas sementes, porém, os cotilédones, quando detentores de pigmento verde mais intenso, ficam seriamente comprometidos, com grande quantidade de células deterioradas, o que pode provocar danos na translocação de reservas para o eixo embrionário, no momento da germinação. Nos apontamentos de Adams et al. (1983), a deterioração dos cotilédones pode implicar em prejuízos das enzimas isocitrato liase e malato sintase, que são consideradas enzimas específicas de germinação, devido ao seu exclusivo papel na via do glioxalato. Essa via emprega enzimas e reações que ocorrem no ciclo do ácido cítrico (Krebs), para habilitar a síntese líquida de glicose a partir de triacilgliceróis armazenados. As duas enzimas específicas, não pré-existem numa forma inativa em cotilédones, mas são sintetizadas durante a germinação (Smith et al., 1974).

No teste de comprimento de plântulas (Figura 1), embora a análise estatística não tenha evidenciado diferença significativa entre os tratamentos foi observado visualmente prejuízo no desenvolvimento de plântulas, oriundas de sementes com maior porcentagem de sementes de pigmentação verde. Dan et al. (1987) verificaram maior comprimento de plântulas em lote de maior vigor e justificaram esse fato em razão dessas plântulas serem mais hábeis na utilização de material de reserva existente nos cotilédones. Sementes com cotilédones esverdeados podem sofrer efeitos deletérios causados por deterioração advinda da nãodegradação de cloropigmentos, que de acordo com Fukushima e Lanfer-Marquez (2000) são susceptíveis a muitas reações de degradações, como epimerização, pirólise, hidroxilação, oxidação, fotooxidação ou feofitinização.

A influência ambiental no teste de emergência em campo (Tabela 1) também foi observada e marcaram diferenças significativas entre os três tratamentos, porém, nos tratamentos com sementes esverdeadas, foi salientado o fator negativo da retenção de clorofila. As sementes com resíduos de pigmentos verdes apresentaram menor número de plântulas emergidas e, de forma visível, maior desuniformidade no crescimento das plântulas, em relação às sementes originais e amarelas. Cotilédones esverdeados mostraram sintomas típicos de deterioração e a extensão dessa variou de parcial até quase total nas sementes. Dependendo dessa abrangência, a semente deteriorada originou plântula fraca, com possibilidades de não sustentar a continuidade do desenvolvimento da planta, ou quando não, se tornou uma planta dominada entre as demais. De acordo com Kagawa et al. (1973), sob condições normais, as plântulas emergem e os cotilédones se expandem em folhas completamente funcionais, enquanto as reservas lipídicas são exauridas. Assim, o começo do metabolismo fotossintético está reciprocamente relacionado ao declínio do metabolismo do lipídio, que foi translocado dos cotilédones e usados até que a plântula se torne autotrófica. Na luz dessas observações, torna-se justificável a interrupção do desenvolvimento da

TABELA 2. Médias obtidas de vigor, viabilidade e deterioração por umidade na subclasse DU 4-5, no teste de tetrazólio, em dois lotes de sementes de soja A e B com 11,8\% e 37,4\%, respectivamente de sementes esverdeadas, segmentados em: semente original, semente amarela e semente esverdeada.

\begin{tabular}{lcccccc}
\hline \multirow{2}{*}{ Tratamentos } & \multicolumn{3}{c}{ Tetrazólio (\%) } \\
\cline { 2 - 6 } & \multicolumn{2}{c}{ Vigor } & \multicolumn{2}{c}{ Viabilidade } & \multicolumn{2}{c}{ DU 4-5 } \\
\cline { 2 - 6 } & Lote A & Lote B & Lote A & Lote B & Lote A & Lote B \\
\hline Semente amarela & $68 \mathrm{~A}$ & $46 \mathrm{~A}$ & $81 \mathrm{~A}$ & $68 \mathrm{~A}$ & $8 \mathrm{~B}$ & $16 \mathrm{~A}$ \\
Semente original & $60 \mathrm{~A}$ & $36 \mathrm{~A}$ & $78 \mathrm{~A}$ & $60 \mathrm{AB}$ & $12 \mathrm{~B}$ & $17 \mathrm{~A}$ \\
Semente esverdeada & $44 \mathrm{~B}$ & $18 \mathrm{~B}$ & $68 \mathrm{~A}$ & $45 \mathrm{~B}$ & $20 \mathrm{~A}$ & $22 \mathrm{~A}$ \\
\multicolumn{1}{c}{ CV $(\%)$} & 4,90 & 9,27 & 6,60 & 9,45 & 12,05 & 10,94 \\
\hline
\end{tabular}

Médias seguidas pela mesma letra na coluna, não diferem entre si peloTeste de Tukey ao nível de 5\% de probabilidade de erro. Lote A (original): 11,8\% de sementes esverdeadas e Lote B (original): $37,4 \%$ de sementes esverdeadas. 


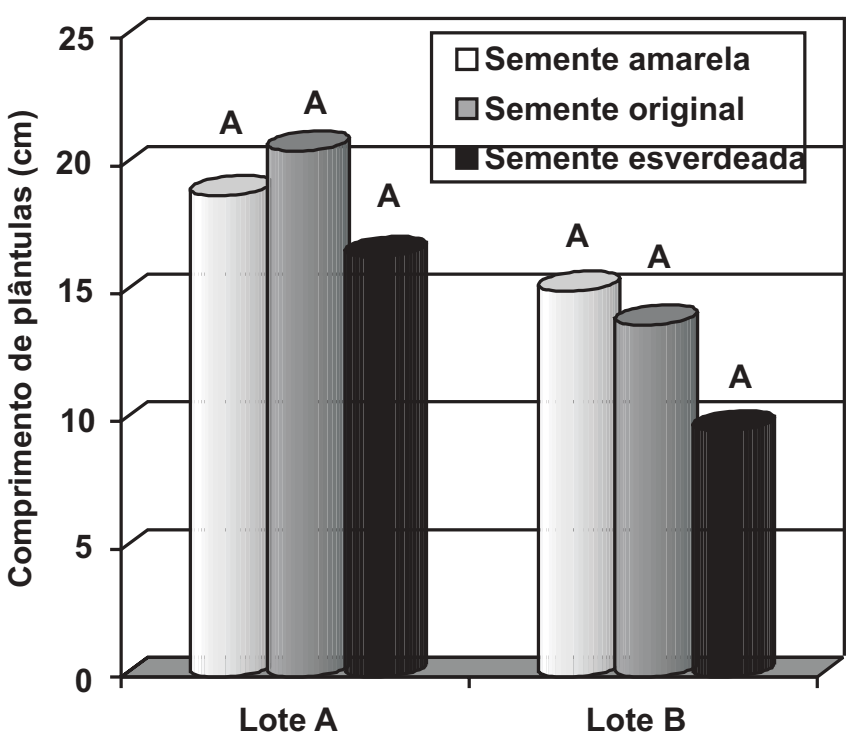

FIGURA 1. Dados médios em porcentagem de comprimento de plântulas (cm) em dois lotes de sementes de soja $\mathrm{A} \mathrm{e}$ B com $11,8 \%$ e $37,4 \%$, respectivamente de sementes esverdeadas, segmentadas em: semente original, semente amarela e semente esverdeada. CV (\%) Lote $A=10,91$ e Lote $B=21,62$

plântula, cuja origem foi de semente com cotilédones esverdeados, a qual apresentou o processo de deterioração avançado, inviabilizando sua continuidade. Observando que essa interrupção do desenvolvimento é dependente da nuance de clorofila nos cotilédones, ou seja, quanto mais intensa a coloração do pigmento, maior a possibilidade de deterioração rápida da semente, fato que foi corroborado nos relatos de França Neto et al. (2005).

$\mathrm{O}$ vigor, medido pela condutividade elétrica (Tabela 1), confirmou a expectativa de menor integridade de membranas das sementes que degradaram parcialmente a clorofila. $\mathrm{O}$ tratamento de sementes esverdeadas apresentou maior quantidade de lixiviados, em relação às sementes originais e amarelas. Conforme visualizado por Adams et al. (1983), em sementes de soja que sofreram processo de maturação e secagem rápida e que não degradaram a clorofila, grande quantidade de fosfato inorgânico, açúcares e proteínas solúveis foram lixiviados durante a embebição, em relação às que secaram lentamente. Esses autores consideraram, ainda, que a secagem rápida pode romper membranas celulares e estruturas internas. Como observado por Wilson e McDonald (1986), a clorofila pode reagir com compostos intermediários de peroxidação de lipídios e a conseqüência primária dessa peroxidação em tecidos pode ser a diminuição da competência respiratória, assim como, o declínio geral da integridade de membranas. Vieira e Krzyzanowski (1999) também relacionaram a quantidade de lixiviados na solução de embebição à integridade das membranas celulares. Caso as membranas tornem-se permeáveis, pode não ocorrer a síntese de enzimas, a elongação celular e a divisão da célula (Harrington, 1973).

Na massa de mil sementes (Tabela 1), a análise estatística computou diferenças significativas entre os tratamentos de sementes esverdeadas em relação às sementes amarelas, nos dois lotes estudados. Foram observados prejuízos em massa média de 3,17 gramas (Lote A) e 7,95 gramas (Lote B), para as sementes com cotilédones esverdeados, valores esses que manifestam o elo da clorofila, além do aspecto fisiológico, também com o aspecto físico das sementes. Medina et al. (1997), também obtiveram menor massa em sementes de soja esverdeadas e verdes, quando comparadas com as sementes amarelas. Jalink et al. (1998) verificaram que amostras com baixo sinal de fluorescência apresentaram maior massa e apontaram as explicações de que as sementes ganharam massa durante a última fase do processo de maturação, ou as sementes de maior massa degradam a clorofila de forma mais efetiva, ou ainda, as sementes de baixo sinal de fluorescência estavam mais velhas na planta e tiveram desenvolvimento sob condições mais favoráveis. Egli (1975) observou o aumento de peso nas sementes relacionado à capacidade da comunidade de plantas fixar carbono durante o período de enchimento ou a translocação do carboidrato armazenado para outras partes da planta. Dornbos et al. (1989) evidenciaram que a massa da semente, um componente primário de produção, é determinada pela sua taxa de desenvolvimento e pela duração do período de enchimento. Consideraram, também, uma possível relação entre massa de semente e o vigor, quando essa massa é reduzida pelo estresse ambiental, situação essa adequada para explicar menor vigor das sementes esverdeadas.

Com os resultados, abordagens e informações neste estudo, o que se pode enfatizar é a importância das condições ambientais, durante as fases reprodutivas e, de forma especial, na deposição de reservas das sementes e processos de amadurecimento, épocas que também as clorofilas são degradadas.

\section{CONCLUSÕES}

Clorofila é indicativo de redução do potencial fisiológico em sementes de soja.

Diferentes quantidades de sementes esverdeadas interferem, em maior ou menor intensidade, no potencial 
fisiológico em soja.

Em sementes detentoras de pigmento verde, o índice de deterioração por umidade, na subclasse DU 4-5 do teste de tetrazólio, avalia o risco da armazenagem do lote.

\section{REFERÊNCIAS}

ADAMS, C.A.; FJERSTAD, M.C.; RINNE, R.W. Characteristics of soybean seed maturation: necessity for slow dehydration. Crop Science, Madison, v.23, n.2, p.265-267, 1983.

ASSOCIATION OF OFFICIAL SEED ANALYSTS. Seed vigour testing handbook. East Lasing, 1983. 88p. (AOSA. Contribuition, 32).

BRASIL. Ministério da Agricultura e da Reforma Agrária. Regras para análise de sementes. Brasília: SNAD/DNDV/CLAV, 1992. $365 \mathrm{p}$.

CÂMARA, G.M.S.; HEIFFIG, L.S. Fisiologia, ambiente e rendimento da cultura da soja. In: CÂMARA, G.M.S. Soja: tecnologia da produção II. Piracicaba: G.M.S. CÂMARA, 2000. p.81-120.

COSTA, N.P.; FRANÇA-NETO, J.B.; PEREIRA, J.E.; MESQUITA, C.M.; KRZYZANOWSKI, F.C.; HENNING, A. A. Efeito de sementes verdes na qualidade fisiológica de sementes de soja. Revista Brasileira de Sementes, Brasília, v. 23, n.2, p.102-107, 2001.

DAN, E.L.; MELLO, V.D.C.; WETZEL, C.T.; POPINIGIS, F.;ZONTA, E.P. Transferência de matéria seca como método de avaliação do vigor de semente de soja. Revista Brasileira de Sementes, Brasília, v. 9, n.3, p.45-55, 1987.

DORNBOS, D.L.; MULLEN, R.E.; SHIBLES, R.M. Drought stress effects during seed fill on soybean seed germination and vigor. Crop Science, Madison, v.29, n.2, p.476-480, 1989.

EGLI, D.B. Rate of accumulation of dry weigth in seed of soybeans and its relationship to yield. Canadian Journal Plant Science, Ottawa, v.55, n.1, p.215-219, 1975.

ENDO, Y.; USUKI, R.; KANEDA, T. The photoxidative alteration of chlorophylls in methyl linoleate and prooxidant activity of their decomposition products. Agricultural and Biological Chemistry, Tokyo, v.48, n.4, p.985-989, 1984.

FRANÇA NETO, J.B.; KRZYZANOWSKI, F.C.; COSTA, N.P. O teste de tetrazólio em sementes de soja. Londrina: EMBRAPACNPSo, 1998, 72p. (Documentos 116).

FRANÇA NETO, J.B.; PÁDUA, G.P.; CARVALHO, M.M.L.; COSTA, O.; BRUMATTI, P.S.R.; KRZYZANOWSKI, F.C.; COSTA, N.P.; HENNING, A.A.; SANCHES, D.P. Sementes esverdeadas de soja e sua qualidade fisiológica. Londrina: Embrapa Soja, 2005. 8p. (Embrapa Soja. Circular Técnica, 38).

FUKUSHIMA, P.S.; LANFER-MARQUEZ, U.M. Chlorophyll derivates of soybean during maturation and drying conditions. Proceedings of the Third International Soybean Processing and Utilization Conference, Tsukuba, 2000, p.87-88.

GUIAMÉT, J.J.; SCHWARTZ, E.; PICHERSKY, E.; NOODÉN, L.D.
Characterization of cytoplasmic and nuclear mutations affecting chlorophyll and chlorophyll-binding proteins during senescence in soybean. Plant Physiology, Rockville, v.96, n.1, p.227-231, 1991.

HARRINGTON, J.F. Biochemical basis of seed longevity. Seed Science and Technology, Zürich, v.1, n.2, p.453-461, 1973.

JALINK, H.; VAN DER SCHOOR, R. FRANDAS, A.; VAN PIJLEN, J.G. Chlorophyll fluorescence of Brassica oleracea seeds as a non-destructive marker for seed maturity and seed performance. Seed Science Research, New York, v.8, n.4, p. 437-443, 1998.

JALINK, H.; VAN DER SCHOOR, R.; BIRNBAUM, Y.E.; BINO, R.J. Seed chlorophyll content as an indicator for seed maturity and seed quality. Acta Horticulturae, Wageningen, v.504, n.12, p. 219-228, 1999.

KAGAWA, T.; McGREGOR, D.I.; BEEVERS, H. Development of enzymes in the cotyledons of watermelon seedlings. Plant Physiology, Baltimore, v.51, n.1, p.66-71, 1973.

MARCOS FILHO, J. Testes de vigor: importância e utilização. In: KRZYZANOWSKI, F.C.; VIEIRA, R.D.; FRANÇA-NETO, J.B. Vigor de sementes: conceitos e testes. Londrina: ABRATES, 1999. Cap.1, p.1.1-1.20.

MARCOS FILHO, J. Teste de envelhecimento acelerado. In: KRZYZANOWSKI, F.C.; VIEIRA, R.D.; FRANÇA-NETO, J.B. Vigor de sementes: conceitos e testes. Londrina: ABRATES, 1999. Cap.3, p.3.1-3.24.

McINTYRE, G.I. The role of water in the regulation of plant development. Canadian Journal of Botany, Ottawa, v.65, n.7, p.1287-1298, 1987.

MEDINA, P.F.; LAGO, A.A.; RAZERA, L.F.; MAEDA, J.A. Composição física e qualidade fisiológica de lotes de sementes de soja com incidência de sementes esverdeadas. In: CONGRESSO BRASILEIRO DE SEMENTES, 10. 1997, Foz do Iguaçu. Resumos. Curitiba: Informativo ABRATES, 1997. v.7, n.1/2, p.36.

MENDONÇA, E.A.F.; RAMOS, N.P.; FESSEL, S.A.; SADER, R. Teste de deterioração controlada em sementes de brócoli (Brassica oleraceae L.) var. itálica. Revista Brasileira de Sementes. Brasília, v.22, n.1, p.280-287, 2000.

NAKAGAWA, J. Testes de vigor baseados no desempenho das plântulas. In: KRZYZANOWSKI, F.C.; VIEIRA, R.D.; FRANÇANETO, J.B. Vigor de sementes: conceitos e testes. Londrina: ABRATES, 1999. Cap.2, p.2.9-2.13.

NOODÉN, L.D. Integration of soybean pod development and monocarpic senescence. Physiology Plant, Copenhagen, v.62, fasc.2, p.273-284, 1984.

PRITCHARD, J.R. Oilseed quality requirements for processing. Journal American Chemistry Society, Champaign, v.60, n.2, p.174-184, 1983.

SINNECKER, P. Degradação da clorofila durante a maturação e secagem de semente de soja. São Paulo: USP. 2002. 103P. Tese (Doutorado em Ciência dos Alimentos). Faculdade de Ciências Farmacêuticas,Universidade de São Paulo, 2002.

SMITH, R.H.; SCHUBERT, A.M.; BENEDICT, C.R. The development of isocitric lyase activity in germinating cotton seed. Plant Physiology, Baltimore, v.54, n.2, p.197-200, 1974.

STECKEL, J. R.A.; GRAY, D.; ROWSE, H.R. Relationships 
between indices of seed maturity and carrot seed quality. Annals of Applied Biology, Cambridge, v.114, n.1, p.177-183, 1989.

USUKI, R.; ENDO, Y.; KANED, T. Prooxidant activities of chlorophylls and pheophytins on the photooxidation of edible oils. Agricultural and Biological Chemistry, Tokyo, v.48, n.4, p.991-994, 1984.

VERTUCCI, C.W.; LEOPOLD, A.C. Oxidative processes in soybean and pea seeds. Plant Physiology, Michigan, v.84, n.4, p.1038-1043, 1987.

VIEIRA, R.D.; KRZYZANOWSKI, F.C. Teste de condutividade elétrica. In: KRZYZANOWSKI, F.C.; VIEIRA, R.D.; FRANÇANETO, J.B. Vigor de sementes: conceitos e testes. Londrina: ABRATES, 1999. p.1-26.

WARD, K.; SCARTH, R. DAUN, J.; McVETTY, P.B.E. Effects of genotype and environment on seed chlorophyll degradation during ripening in four cultivars of oilseed rape (Brassica napus). Canadian Journal of Plant Science, Ottawa, v.72, n.3, p.643-649, 1992.

WARD, K.; SCARTH, R. DAUN, J.; VESSEY, J.K. Chlorophyll degradation in summer oilseed rape and summer turnip rape during seed ripening. Canadian Journal of Plant Science, Ottawa, v.75, n.2, p.413-420, 1995.

WILSON, D.O.; McDONALD, M.B. The lipid peroxidation model of seed aging. Seed Science and Technology, Zürich, v.14, p.296300, 1986.

ZONTA, E.P.; MACHADO, A. Sistema de análise estatística para microcomputadores-SANEST. Pelotas: UFPel, Instituto de Física e Matemática. 1986. 150p.

ZORATO, M.F. Teste de tetrazólio modificado. SEED News, Pelotas, ano V, n.4, p.21, 2001. 